\title{
Preparation of microencapsulated PCMs for energy-saving and thermal comfort of buildings
}

\author{
Ashraf Mohamed Heniegal ${ }^{\mathrm{a}}$, Omar Mohamed Omar Ibrahim ${ }^{\mathrm{b}}$, Nour Bassim Frahat ${ }^{\mathrm{b}}{ }^{*}$, Mohamed Amin $^{\mathrm{b}}$
}

\author{
${ }^{a}$ Civil Engineering Department, Faculty of Engineering, Suez University, Egypt. \\ ${ }^{\mathrm{b}}$ Civil and Architectural Constructions Department, Faculty of Technology and Education, Suez University, Egypt. \\ * Corresponding author. E-mail address: nour.bassim@suezuni.edu.eg
}

\begin{abstract}
Energy improvement techniques for buildings are among the modern studies that concentrate on new techniques and methods of saving energy and improving the thermal performance in buildings. This research aims to prepare microencapsulated-PCMs (micro-PCMs) by using local materials and studied the influence of using micro-PCMs on thermal performance improvement and PCMs leakage problems improvement. The micro-PCMs of paraffin wax was prepared as the core PCMs materials while the melamine-formaldehyde polymer was the shell. The micro-PCMs were characterized through scanning electron-microscopy (SEM), energy-dispersive X-ray (EDX) spectrometry, Fourier-transform infrared spectroscopy, and differential scanning calorimetry. Analysis results showed the prepared micro-PCMs present a regular spherical shape and confirm that the formation composite of the shell effectively encapsulated the cores. Furthermore, the absence of chemical interaction between the MF and the PW components. The micro-PCM have the potential for architectural applications in the building envelope to store thermal energy, provide the indoor temperature at a comfortable range, and reduce the consumption energy in buildings.
\end{abstract}

Keywords: Microencapsulation-PCM (micro-PCMs), Energy saving, melamine-formaldehyde polymer, Paraffin wax.

\section{Introduction}

The actual use of PCMs suffers from problems, such as leakage and corrosion, decreases thermal conductivity values, and compatibility concerns [1,2]. Moreover, microencapsulation technologies have attracted renewed attention and are now widely used [1-3]. Microcapsules are mini particles containing functional or core materials by a polymer shell. The core PCMs of the microcapsules cannot be easily affected by the exterior environment due to the shell protection [4,5]. Therefore, microencapsulation with polymeric material shells has received increased attention in the last few decades [6]. Melamine-formaldehyde (MF) possesses a relatively high thermal conductivity, high density, and exhibits good mechanical behavior, making it a good candidate material for the microencapsulation of PCMs. MF has high hardness and resistance to water attacks and different weather conditions [7-9]. Accordingly, the chemical component, core materials can be classified depending on the chemical composition as inorganic and organic PCMs. As a typical organic PCM, paraffin wax (PW) has many merits, like safety, reliability, high heat of fusion, chemical inertness and stability, nontoxicity, no phase segregation, and local availability [10-12]. However, the important undesirable problem is liquid PW leakage through the phase-change process. [11]. Therefore, microencapsulation PW technology is a feasible solution to the ingrained drawbacks of PW [13]. In this regard, many scholars have studied microPCM preparation using PW as the core PCMs material and MF as the shell polymer or other materials. A new micro-PCM organic was developed, and its TES performance was experimentally studied using the MF shell and 1-dodecanol core. The results display that micro-PCM is a promising candidate for decreasing the TES due to its enhanced properties [6]. A nanoencapsulation PCM was prepared with an MF shell and PW core PCM. The results proved that the prepared nanoencapsulation can be applied in thermal performance and latent-heat TES systems because of their good thermal properties and encapsulation efficiency [2]. Micro and 
macro n-dodecanol were fabricated as PCMs utilizing an oil-soluble MF prepolymer, which was etherified through methanol and butanol, as the shell. The investigation showed that the thermal stabilization was slightly enhanced compared with that without an MF shell [14]. Microcapsules were prepared using PW as core PCMs and melamine-urea formaldehyde polymer as the shell under different conditions. The investigation revealed that the reaction temperature was $80^{\circ} \mathrm{C}$, the reaction time was at $2 \mathrm{~h}$, the latent heat of the microcapsules was approximately $134.3 \mathrm{~J} / \mathrm{g}$ to $133.1 \mathrm{~J} / \mathrm{g}$, and the encapsulation efficiency was at $77.1 \%$ [9]. Microcapsules were prepared by etherifying resin at a melamine/formaldehyde/dodecanol molar rate of 1:7:2 as the shell. The impact of etherification and relevant influencing factors on the performance of the microcapsules was studied. The results revealed that the micro-PCMs displayed good performance, good thermal cyclic durability, and outstanding mechanical properties [15].

This investigation aims to prepare and produce micro-PCMs by using local materials of thermal performance improvement, thermal comfort enhancement. First, micro-PCMs with PW as the core material and MF polymer as the shell were prepared. Second, the obtained micro-PCMs were achieved by scanning electron microscopy (SEM), energy dispersive X-ray (EDX) spectroscopy, Fourier transform infrared (FT-IR) spectroscopy, differential scanning calorimetry (DSC).

\section{Experimental Program}

\subsection{Materials}

In this research, PW (Ameeriah-Petroleum Refinery Company, Alexandria, Egypt) with a melting temperature of $41{ }^{\circ} \mathrm{C}$ was utilized as the core material for the PCMs. Melamine and formaldehyde $37 \mathrm{wt} \%$ were acquired from Sprea Misr for Chemicals and Plastics Company (10th of Ramadan, Sharkia, Egypt) for use as shell materials. Hydrochloric $(\mathrm{HCl})$ acid was acquired from Sprea Misr for Chemicals and Plastics Company and applied to control check the polymer $\mathrm{pH}$ and complete the polymerization operation. During the preparation, the materials were utilized without further purification.

\subsection{Preparation of micro-PCMs}

\subsubsection{Polymerization process of micro-PCMs}

The micro-PCMs were prepared based on the in-situ polymerization technique with low energy consumption. PW was utilized as the core material of the PCMs, while MF resins were utilized as the shell material. The micro-PCMs were prepared as follows. The MF prepolymer (resin) was prepared. First, $4.8 \mathrm{~g}$ of melamine (Fluka) and $24 \mathrm{ml}$ of formaldehyde (37 wt $\%$ ) were added into a beaker and then mixed by stirring at $300 \mathrm{rpm}$ for $3 \mathrm{~min}$. Then, the mixture was heated while stirring for $15 \mathrm{~min}$ at $40{ }^{\circ} \mathrm{C}$ until transparent and sticky. The stirring with a magnetic stirrer continued at $600 \mathrm{rpm}$ for another $3 \mathrm{~min}$. After obtaining the primary resin, 0.6 $\mathrm{ml}$ of $\mathrm{HCl}$ acid $(8 \mathrm{~mol}$ ) was added to the $\mathrm{MF}$ and stirred continuously for approximately $5 \mathrm{~min}$. Thus, the $\mathrm{pH}$ value of the primary resin mixture was adjusted to 4-5 after completely dropping the $\mathrm{HCl}$ acid. Second, the stirring speed was increased to $1000 \mathrm{rpm}$. Then, $10 \mathrm{gm}$ of PW and $5 \mathrm{ml}$ of vegetable edible oil were successively added into the beaker. Subsequently, the mixture was automatically cooled while stirring continuously for approximately $15 \mathrm{~min}$. When the polymerization operation was completed, the MF polymer grid was produces connected to an external surface of the PW. Adding distilled water for washing as observing the remaining wax will up to the surface, while micro-PCM were landed to down. Finally, white powders (microencapsulated PCMs) filtered and washed by distilled water and were dried in a drying oven at a rate of $100{ }^{\circ} \mathrm{C}$ for 4 h. Fig. 1 displays the schematic diagram of micro-PCMs for PW with MF shell, while Fig. 2 shown chemical reaction process scheme for micro-PCMs. This preparation procedure is similar to the procedure in the works of Zhang, Han et al., and H.S. Mohammed et al. [1,2,16]. 


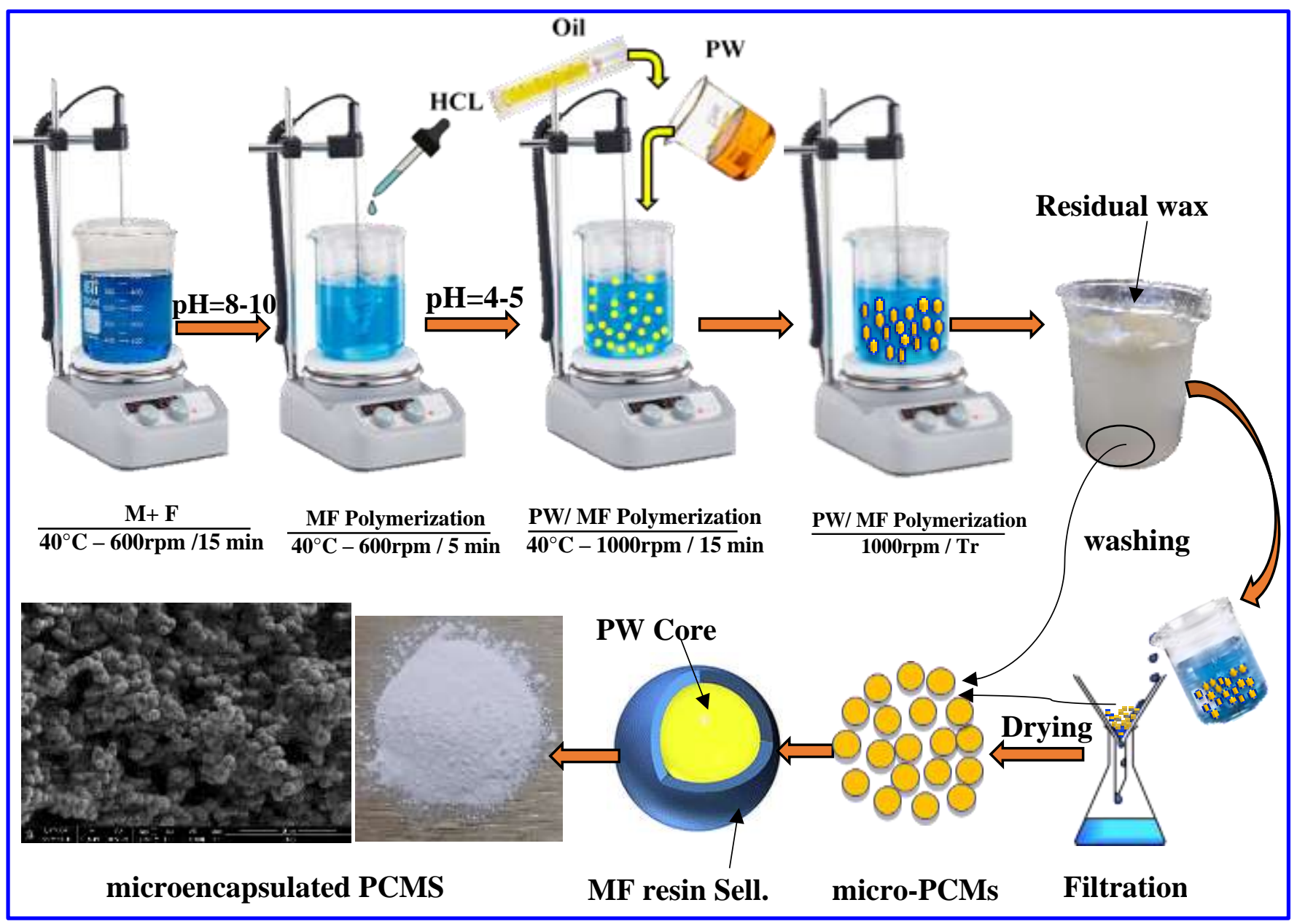

Fig. 1. Schematic diagram of the preparation process for micro-PCMs.

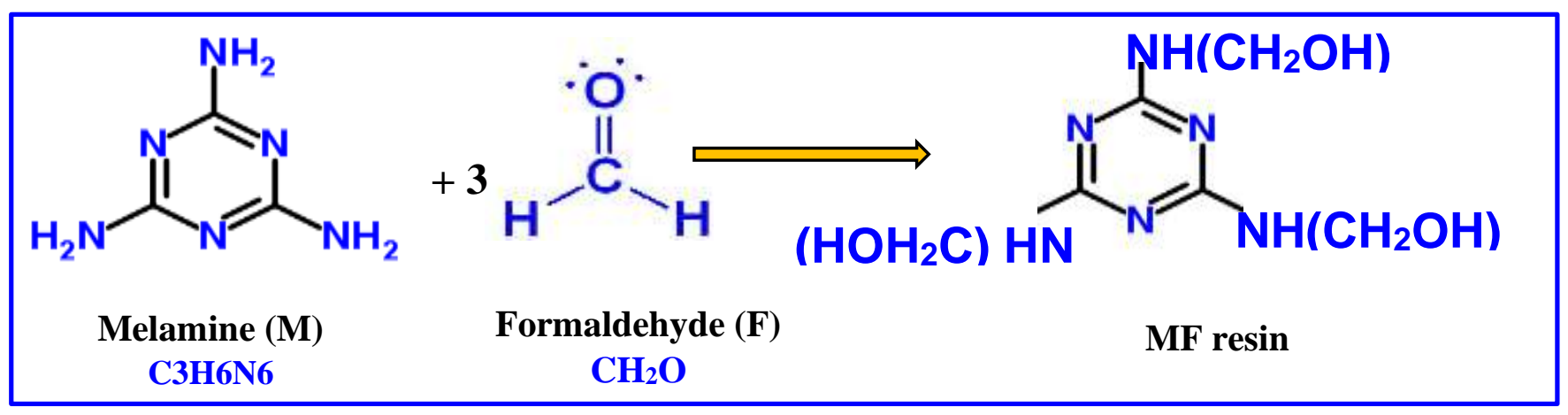

Fig. 2. Chemical reaction scheme for micro-PCMs.

\subsubsection{Characterization of micro-PCMs}

\section{Scanning Electronic Microscope (SEM)}

The microstructure of the micro-PCMs-integrated mortar was obtained using an FEI QUANTA 200 (USA) scanning electronic microscope Fig. 3.

\section{Energy Dispersive X-ray (EDX)}

The atomic percentage of each element was determined by an EDX spectrometer (HITACHI S-4700) as an additional tool for the semiquantitative analysis of the prepared micro-PCMs Fig. 3. 


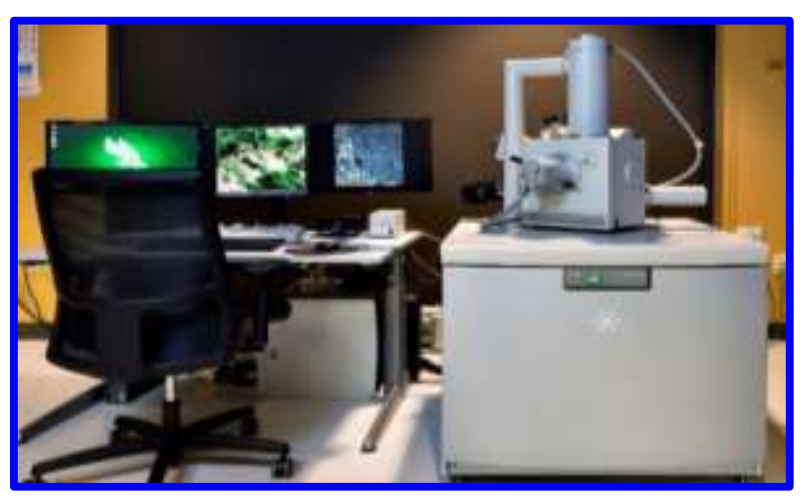

Fig. 3. FEI QUANTA 200 (USA) scanning electronic microscope.

\section{Fourier Transform Infrared (FT-IR)}

The chemical structure of the micro-PCMs was analyzed using an FT-IR spectrometer (Bruker, ALPHAII, Germany) with the $\mathrm{KBr}$ sampling method (Fig. 4). The FT-IR spectra were recorded on a $\mathrm{KBr}$ pellet in the frequency range of $4000 \mathrm{~cm}^{-1}$ to $400 \mathrm{~cm}^{-1}$, and the wavenumber accuracy of the FT-IR was $0.01 \mathrm{~cm}^{-1}$.

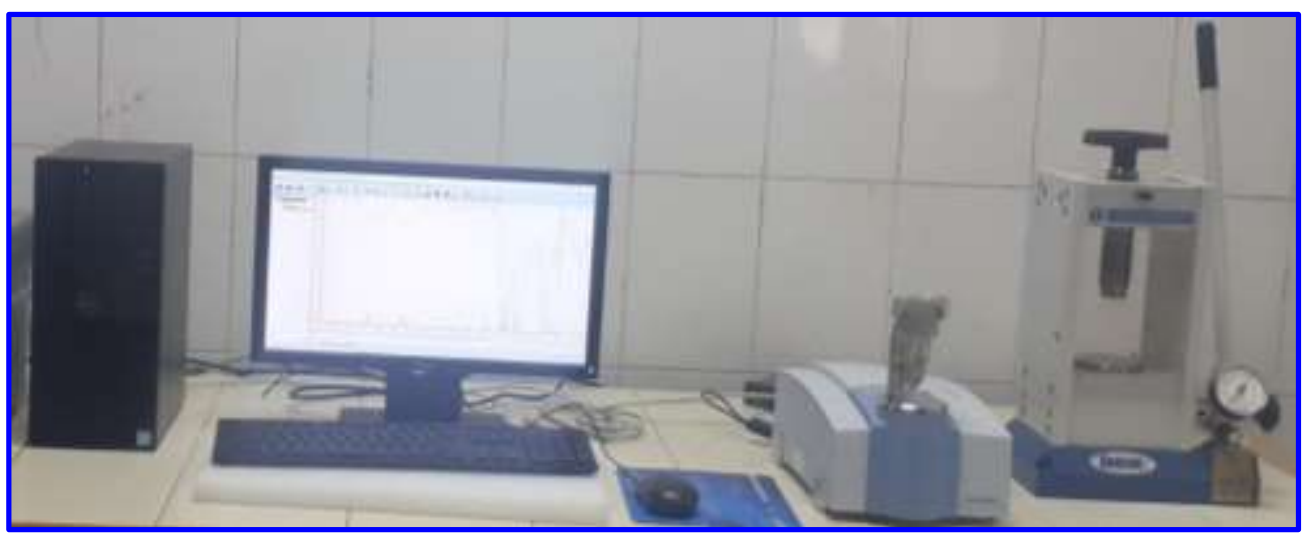

Fig. 4 FT-IR spectrometer (Bruker, ALPHAII, Germany).

\section{Differential Scanning Calorimetry test (DSC)}

Thermal energy storage properties of the prepared mix PCMs such as melting point and latent heat values were measured by a DSC instrument (Model DSC Q2000 TA Instruments, USA) Fig.5. The measurements were carried out at a heating rate of $5{ }^{\circ} \mathrm{C} / \mathrm{min}$ and range of $0-80{ }^{\circ} \mathrm{C}$ under a constant stream of nitrogen at a flow rate of $50 \mathrm{ml} / \mathrm{min}$, and samples size about $5-7 \mathrm{mg}$.

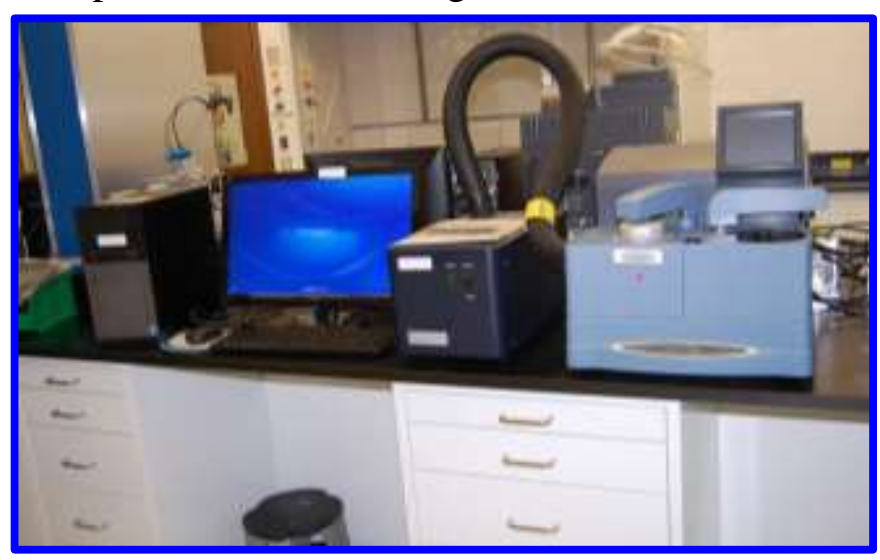

Fig. 5. DSC instrument (Model DSC Q2000 TA Instruments, USA). 


\section{Results and discussion}

\subsection{Scanning electron microscopy (SEM)}

Fig. 6 present the SEM micrographs of the micro-PCMs synthesized with MF as the shell material and PW as the core material. Micro-PCMs have full sphericity, regular and steady morphology, a smooth surface without breaks and depressions, and nearly uniform particle size. SEM imaging shows an enhanced homogeneity in the size distribution of the micro-PCMs, the optimization of encapsulation with respect to the PCM amount is shown in Fig. 6a, where the spherical morphology of the MF shell suggests the excellent shell encapsulation of each PCM, preventing any leakage during the solid to liquid phase change process. The particle size average of the prepared micro-PCMs is $0.92-1.25 \mu \mathrm{m}$ (Fig. 6d). The preparation micro-PCMs characteristic is compatible with previous studies[2,5,8]. Further enhancement investigations are accordingly encouraged.

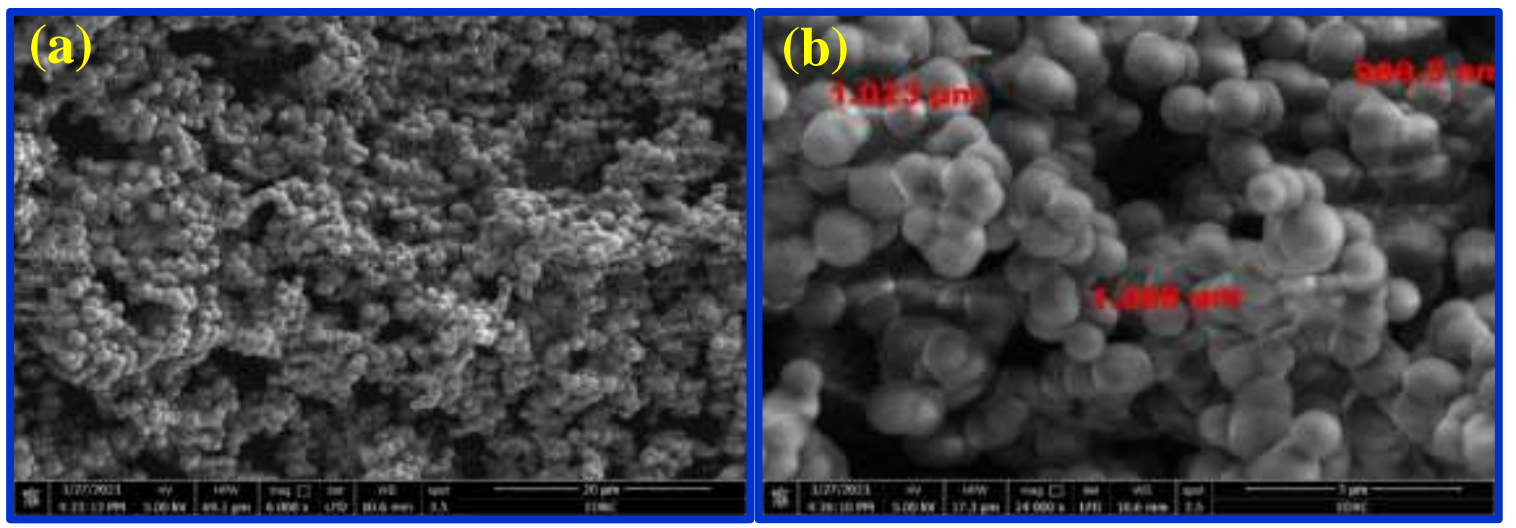

Fig. 6. SEM images of (a) micro-PCMs at $6000 \mathrm{X}$ and (b) micro-PCMs at $24000 \mathrm{X}$.

\subsection{Energy-dispersive X-ray spectroscopy (EDX)}

The EDX spectrometry results of the micro-PCMs are presented in Fig. 7, revealing that the weight percentages of carbon $(\mathrm{C})$, nitrogen $(\mathrm{N})$, and oxygen $(\mathrm{O})$ were $35.62 \%, 47.75 \%$, and $15.7 \%$, respectively. The presence of nitrogen in the micro-PCM can be attributed to the amine (shell material) and that of oxygen and carbon to the organic material (PW/PCMs) [6,8]. Similar findings have been reported for different kinds of PCM core with an MF shell. Consequently, the EDX spectroscopy sanctioned the formation composite of the MF shell, which effectively encapsulates the PW core as micro-PCMs.

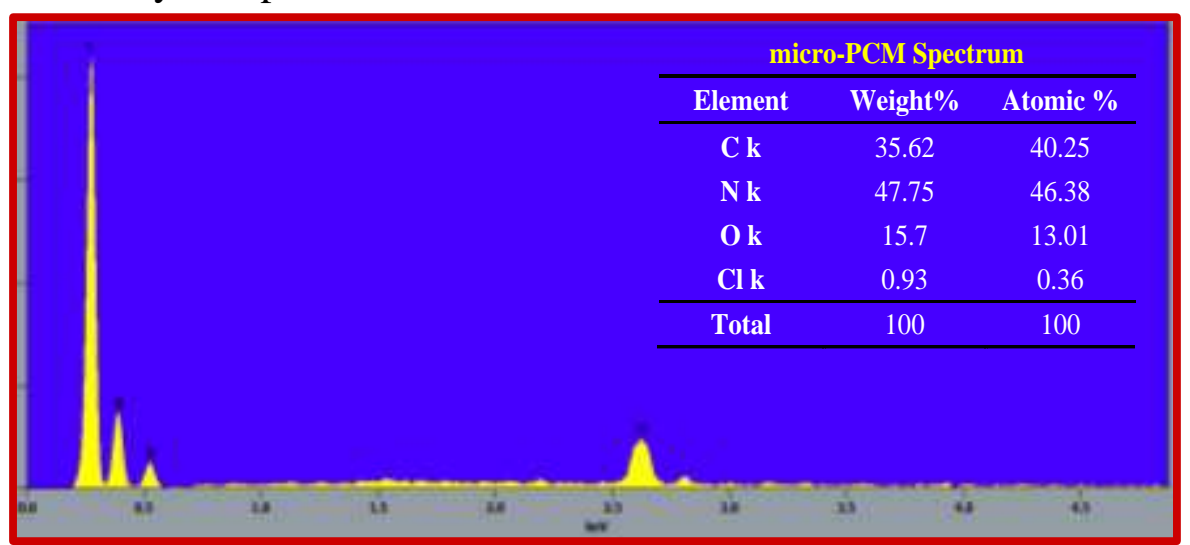

Fig. 7. The energy dispersive X-ray spectrometer EDX of the micro-PCM. 


\subsection{FT-IR spectra of micro-PCM}

The SEM images and EDX results of the micro-PCMs show that the MF resin as the shell was successfully manufactured on the surface of the PW core droplets, preventing the leakage of melted PW, thereby solving the inherent drawback of solid-liquid PCMs. To analyze the interaction between MF resin and PW, FT-IR was used to characterize the PW, the MF resin, and the micro-PCMs, and the results are illustrated in Fig. 8. Fig. 8a represents the FT-IR spectrum of PW. The peaks at 2957 and $2848 \mathrm{~cm}^{-1}$ are characteristic of C-H stretching vibrations, the peak at $1464 \mathrm{~cm}^{-1}$ corresponds to the $\mathrm{C}$ single bond $\mathrm{H}$ bending vibration, and the peak at 724 $\mathrm{cm}^{-1}$ represents the in-plane rocking vibration of $\mathrm{CH} 2$. These absorption peaks are the characteristic of paraffin compounds. Fig. $8 \mathrm{~b}$ presents the FT-IR spectrum of MF resin, and the peak around $3328 \mathrm{~cm}^{-1}$ is the characteristic wide band responsible for hydroxyl, imino, and amino stretching. The peaks at 2917 and 1542 $\mathrm{cm}^{-1}$ are assigned to the alkyl $\mathrm{C}-\mathrm{H}$ stretching vibration and the $\mathrm{C}-\mathrm{N}$ multiple stretching in the triazine ring, respectively. The $\mathrm{C}-\mathrm{H}$ bending vibrations in the methylene group is observed at 1448 and $1337 \mathrm{~cm}^{-1}$ due to the methylene bridges. The characteristic peak of the $\mathrm{C}-\mathrm{N}$ vibration appears at $1155 \mathrm{~cm}^{-1}$, while the characteristic triazine ring bending appears at $808 \mathrm{~cm}^{-1}$, resembling the stretching vibration of triazine rings $[14,17,18]$. Fig. $8 \mathrm{c}$ shows the FT-IR spectrum of the micro-PCMs, indicating that all the corresponding peaks for PW and MF resin can be clearly distinguished in the spectrum of micro-PCMs without new distinct absorption peaks. The result verifies the absence of chemical interaction between the PW core and the MF resin shell, thereby confirming the successful encapsulation of the PW core by the MF shell materials. This result analysis is consistent with that in the literature $[2,6,19]$.

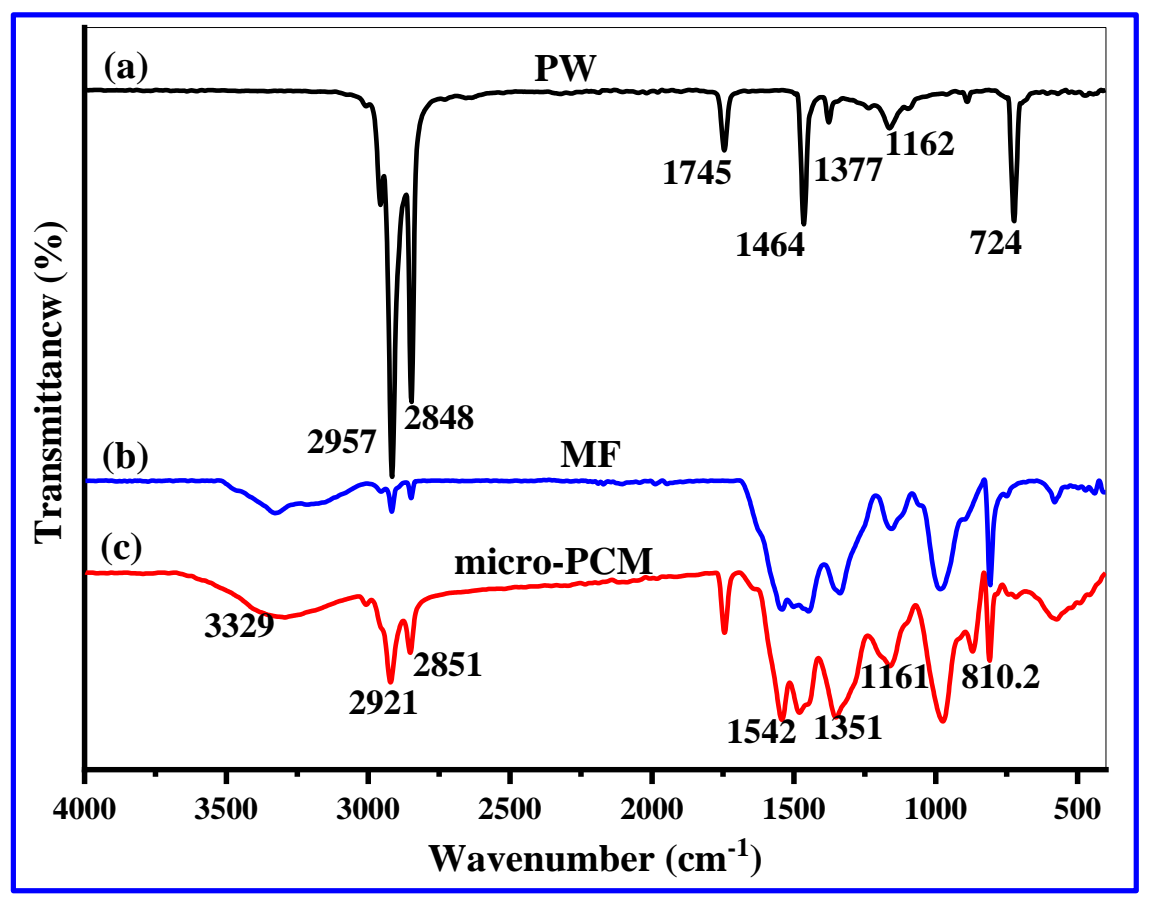

Fig. 8. FT-IR spectra of (a) PW, (b) MF resin, (c) micro-PCMs. 


\subsection{DSC analysis of micro-PCMs}

The phase change temperature (melting point) and latent heat of the prepared micro-PCMs and PW were measured by DSC analysis. The DSC analysis curves of the melting temperature and latent heat of the PW and micro-PCMs are displayed in Figs. 9. The DSC analysis curves of the prepared micro-PCMs at the melting and solidification processes are similar to those of PW, which is another evidence of the successful encapsulation of PW using MF resin. These analyses are consistent with the results given in Refs. [2,20-22]. The melting temperature of the prepared micro-PCMs composite was determined to be $40.70{ }^{\circ} \mathrm{C}$, which is consistent with that of PW (i.e., $41.15^{\circ} \mathrm{C}$ ). DSC analysis indicates that the melting temperatures of microPCMs decreased slightly compared with that of pure PW due to the occurrence and existence of MF encapsulated materials. Meanwhile, the micro-PCMs displayed stable phase change behaviors as indicated by the curve, which includes the main peak like that of the pure PW shown in the DSC analysis curves. Which, micro-PCMs are suitable for different temperature- thermal energy storage applications in buildings. The prepared micro-PCMs have a latent heat of approximately $121.42 \mathrm{~J} / \mathrm{g}$ compared to the $179.57 \mathrm{~J} / \mathrm{g}$ of pure PW. The latent heat of the micro-PCMs changed slightly because of the decrease in PW content in the core prepared with micro-PCMs $[2,6,18,19,23]$. Encapsulation ratio (ER) is one of the important parameters in the study of encapsulated phase change materials for TES. The ER can be determined by the equation below (1) [6]. The ER of micro-PCMs is at $67.611 \%$ for the same PW content $[2,6,19]$. This DSC analysis indicates that the prepared micro-PCMs have substantial thermal properties and thermal energy storage potential and can be used for energy saving in buildings through the reduction of cooling loads.

$$
E R=\left(\triangle H_{\text {Micro-PCMs }} / \triangle H_{P W}\right) * 100 \%[6]
$$

Where, $(E R)$ the encapsulation ratio of the Micro-PCMs; $\left(\triangle H_{\text {Micro-PCMs })}\right.$ is the latent heats of the prepared Micro-PCMs; $\left(\triangle H_{P W}\right)$ is the latent heats of the PW. 


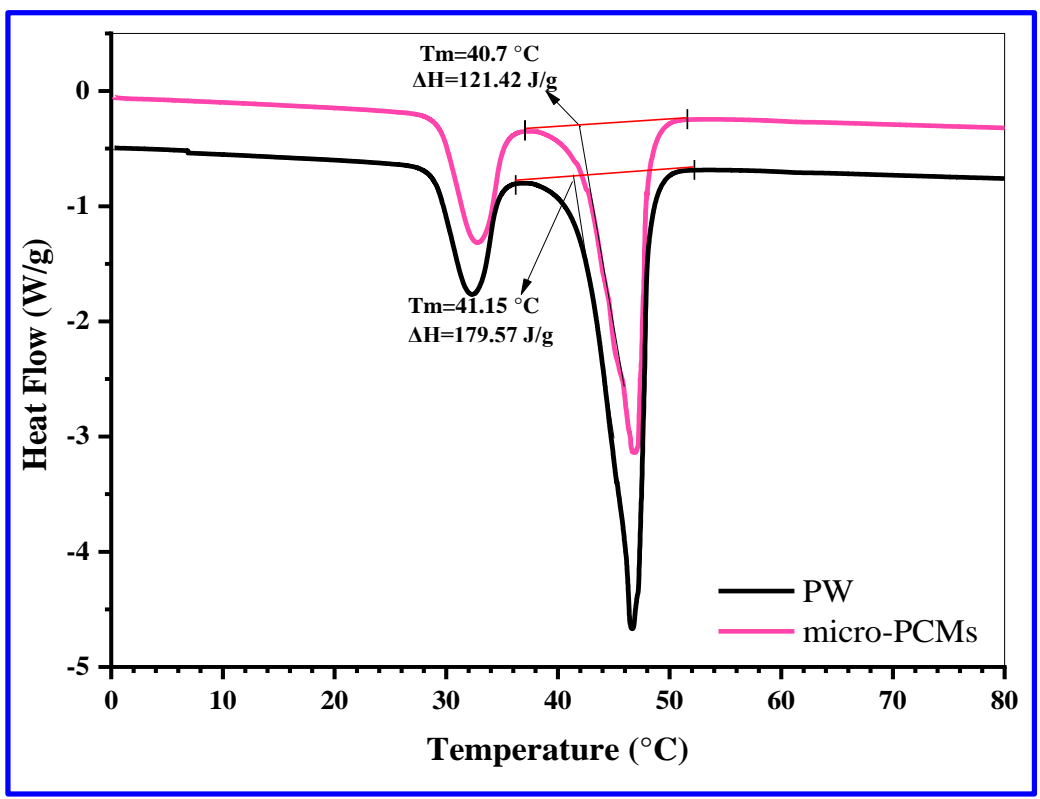

Fig. 9. DSC analysis curves of the pure paraffin wax (PW) and micro-PCMs specimens.

\section{Conclusions}

The following conclusions can be drawn from the investigation carried out in this study:

1- The SEM and EDX results indicate that the micro-PCMs prepared have a regular spherical shape with a smooth surface and a particle size of approximately $0.92-1.25 \mu \mathrm{m}$. Furthermore, the formation composite of the MF shell effectively encapsulates the PW cores as micro-PCMs.

2- The FT-IR spectrum analysis of the micro-PCMs shows no chemical interaction between the PW core and the MF resin shell, also confirming that the PW core was successfully and completely encapsulated with the MF shell materials.

3- DSC analysis indicates that the prepared micro-PCMs had an obvious latent heat of $121.42 \mathrm{~J} / \mathrm{g}$, and the melting point of the micro-PCMs was very near that of pure PW, which is another dominant evidence of the successful encapsulation of PW by the MF shell, with an encapsulation ratio of $67.611 \%$. The thermal energy storage potential can be used to save energy in construction with micro-PCMs.

4- The DSC test analysis of micro-PCMs shows substantial and good TES potential for different temperaturepassive solar cooling and heating applications in buildings, leading to energy-saving constructions.

5- Therefore, based on the aforesaid results, using micro-PCMs in the building has excellent benefits. use micro-PCMs in building envelopes to provide thermal comfort, improve and maintain the indoor temperature at a comfortable range, and reduce the energy consumption in buildings.

However, to achieve realistic thermal performance results, practice applied investigations should be conducted under real climatic conditions. Additionally, further study should be conducted on using microPCMs and their effect on the mechanical and physical properties of cement mortar and concrete.

\section{Acknowledgments}

The authors sincerely thank the laboratory of Civil Constructions Dep., Faculty of Technology and Education, and Chemistry laboratory, Faculty of Science, Suez University, Egypt for their support. Also, the authors wish to thank Sprea Misr for Chemicals and Plastics Company,10th of Ramadan, Sharkia, Egypt for their support of pure materials in this work. The cooperating of Dr. Sally Sayed Gharib and MSc. student, AbdElrhman Essam, for carrying out some of the experimental work is also acknowledged. 


\section{References}

[1] Han P, Lu L, Qiu X, Tang Y, Wang J. Preparation and characterization of macrocapsules containing microencapsulated PCMs (phase change materials) for thermal energy storage. Energy 2015;91:5319. https://doi.org/10.1016/j.energy.2015.08.001.

[2] Zhang N, Yuan Y. Synthesis and thermal properties of nanoencapsulation of paraffin as phase change material for latent heat thermal energy storage. Energy and Built Environment 2020;1:410-6. https://doi.org/10.1016/j.enbenv.2020.04.003.

[3] Nejman A, Cieślak M, Gajdzicki B, Goetzendorf-Grabowska B, Karaszewska A. Methods of PCM microcapsules application and the thermal properties of modified knitted fabric. Thermochimica Acta 2014;589. https://doi.org/10.1016/j.tca.2014.05.037.

[4] Pascu O, Garcia-Valls R, Giamberini M. Interfacial polymerization of an epoxy resin and carboxylic acids for the synthesis of microcapsules. Polymer International 2008;57. https://doi.org/10.1002/pi.2438.

[5] Lu S, Shen T, Xing J, Song Q, Xin C. Preparation, characterization, and thermal stability of doublecomposition shell microencapsulated phase change material by interfacial polymerization. Colloid and Polymer Science 2017;295. https://doi.org/10.1007/s00396-017-4189-3.

[6] Kumar GN, Al-Aifan B, Parameshwaran R, Ram VV. Facile synthesis of microencapsulated 1dodecanol/melamine-formaldehyde phase change material using in-situ polymerization for thermal energy storage. Colloids and Surfaces A: Physicochemical and Engineering Aspects 2021;610. https://doi.org/10.1016/j.colsurfa.2020.125698.

[7] Su W, Darkwa J, Kokogiannakis G. Review of solid-liquid phase change materials and their encapsulation technologies. Renewable and Sustainable Energy Reviews 2015;48. https://doi.org/10.1016/j.rser.2015.04.044.

[8] Su W, Darkwa J, Kokogiannakis G. Nanosilicon dioxide hydrosol as surfactant for preparation of microencapsulated phase change materials for thermal energy storage in buildings. International Journal of Low-Carbon Technologies 2018;13. https://doi.org/10.1093/ijlct/cty032.

[9] Han S, Chen Y, Lyu S, Chen Z, Wang S, Fu F. Effects of processing conditions on the properties of paraffin/melamine-urea-formaldehyde microcapsules prepared by in situ polymerization. Colloids and Surfaces A: Physicochemical and Engineering Aspects 2020;585. https://doi.org/10.1016/j.colsurfa.2019.124046.

[10] Heniegal AM, Omar Ibrahim OM, Frahat NB, Amin M. New Techniques for the Energy Saving of Sustainable Buildings by Using Phase Change Materials The Combined Effect of Phase Change Materials and Pumice Fine aggregates on Energy Saving of Sustainable Buildings. Journal of Building Engineering 2021. https://doi.org/10.1016/j.jobe.2021.102418.

[11] Zhang N, Yuan Y, Cao X, Du Y, Zhang Z, Gui Y. Latent Heat Thermal Energy Storage Systems with Solid-Liquid Phase Change Materials: A Review. Advanced Engineering Materials 2018;20. https://doi.org/10.1002/adem.201700753.

[12] Ghoghaei MS, Mahmoudian A, Mohammadi O, Shafii MB, Jafari Mosleh H, Zandieh M, et al. A review on the applications of micro-/nano-encapsulated phase change material slurry in heat transfer and thermal storage systems. Journal of Thermal Analysis and Calorimetry 2020. https://doi.org/10.1007/s10973-020-09697-6.

[13] Qiu L, Ouyang Y, Feng Y, Zhang X. Review on micro/nano phase change materials for solar thermal applications. Renewable Energy 2019;140. https://doi.org/10.1016/j.renene.2019.03.088.

[14] Huang R, Li W, Wang J, Zhang X. Effects of oil-soluble etherified melamine-formaldehyde prepolymers on: In situ microencapsulation and macroencapsulation of $\mathrm{n}$-dodecanol. New Journal of Chemistry 2017;41. https://doi.org/10.1039/c7nj01528c.

[15] Geng X, Huang R, Zhang X, Li W. Research on long-chain alkanol etherified melamineformaldehyde resin MicroPCMs for energy storage. Energy 2021;214. https://doi.org/10.1016/j.energy.2020.119029.

[16] H.S.mohammed, S.M.Abbas SSM. A New Method For Preparation of Microencapsulated Phase Change Materials (PCMs) For Low Coast Energy in Cooling of Building. Ibn Al-Haitham Journal for Pure and Applied Science 2012;25:304-10.

[17] Wu S, Zhang P, Xu Z, Chen Z, Gao Y. Preparation of 1-dodecanol microcapsules with cellulose 
nanofibers-modified melamine-formaldehyde resin as a potential phase change material. Materials Research Express 2019;6. https://doi.org/10.1088/2053-1591/ab4a5f.

[18] Ho CJ, Chang PC, Yan WM, Amani M. Microencapsulated n-eicosane PCM suspensions: Thermophysical properties measurement and modeling. International Journal of Heat and Mass Transfer 2018;125. https://doi.org/10.1016/j.ijheatmasstransfer.2018.04.147.

[19] Paneliya S, Khanna S, Utsav, Singh AP, Patel YK, Vanpariya A, et al. Core shell paraffin/silica nanocomposite: A promising phase change material for thermal energy storage. Renewable Energy 2020. https://doi.org/10.1016/j.renene.2020.11.118.

[20] Li W, Zhang X xiang, Wang X chen, Tang G yi, Shi H feng. Fabrication and morphological characterization of microencapsulated phase change materials (MicroPCMs) and macrocapsules containing MicroPCMs for thermal energy storage. Energy 2012;38. https://doi.org/10.1016/j.energy.2011.12.005.

[21] Yanshan L, Shujun W, Hongyan L, Fanbin M, Huanqing M, Wangang Z. Preparation and characterization of melamine/formaldehyde/polyethylene glycol crosslinking copolymers as solidsolid phase change materials. Solar Energy Materials and Solar Cells 2014;127. https://doi.org/10.1016/j.solmat.2014.04.013.

[22] Hu D, Wang Z, Ma W. Fabrication and characterization of a novel polyurethane microencapsulated phase change material for thermal energy storage. Progress in Organic Coatings 2021;151. https://doi.org/10.1016/j.porgcoat.2020.106006.

[23] Huo JH, Peng ZG, Feng Q. Synthesis and properties of microencapsulated phase change material with a urea-formaldehyde resin shell and paraffin wax core. Journal of Applied Polymer Science 2020;137. https://doi.org/10.1002/app.48578.

$\begin{array}{ll}\begin{array}{l}\text { Nomenclature } \\ \text { Latin letters }\end{array} \\ \text { ER } \\ \text { Tm } \\ \text { Greek letters } & \text { Encapsulation ratio } \\ \Delta \mathrm{H} & \text { Lelting point } \\ \Delta \mathrm{H}_{\text {Micro-PCMs }} & \text { Latent heat }(\mathrm{kJ} / \mathrm{kg}) \\ \Delta \mathrm{H}_{\mathrm{PW}} & \text { Latent heats of the PW } \\ \text { Abbreviations } & \\ \text { PCMs } & \text { Phase change materials } \\ \text { micro-PCMs } & \text { Microencapsulated phase change materials } \\ \text { PW } & \text { Paraffin wax } \\ \text { MF } & \text { Melamine-formaldehyde } \\ \text { HCL } & \text { Hydrochloric acid } \\ \text { SEM } & \text { Scanning electron microscope } \\ \text { EDX } & \text { Energy-dispersive X-ray spectrometer } \\ \text { FT-IR } & \text { Fourier transforms infrared } \\ \text { DSC } & \text { Differential scanning calorimetry }\end{array}$

